\title{
Determinación del contenido de escorias en los cementos siderúrgicos

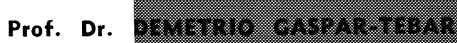

\section{INTRODUCCION}

Los cementos siderúrgicos son conglomerantes hidráulicos preparados con mezclas muy íntimas constituidas, fundamentalmente, por escoria básica granulada, obtenida de procesos siderúrgicos, clínker de cemento portland y sulfato cálcico en distintas proporciones (1) ; mezclas que se preparan por molturación conjunta de los componentes mencionados (2) (3) (4). Las mezclas, aún cuando no es recomendable, también se pueden realizar a partir de los componentes molidos por separado.

Los cementos de escorias se encuentran normalizados en numerosos países fijando, fundamentalmente, la cantidad de escoria de la mezcla así como las características químicas y fisicomecánicas de los mismos.

Las recomendaciones ISO (3) admiten dos clases principales de cementos de escorias según que estén compuestos de clínker de cemento portland y escoria granulada de horno alto (cementos siderúrgicos) o de escorias granuladas y sulfato cálcico con una adición de cal, clínker de cemento portland o cemento portland, en una cantidad máxima de $5 \%$ (cementos sobresulfatados). Dichas recomendaciones, teniendo en cuenta la cantidad de escoria presente incluyen las clases de cemento siderúrgico que se citan en la tabla 1 (3) (5).

TAB L A 1

\begin{tabular}{|l|c|}
\hline \multicolumn{1}{|c|}{ Clase } & $\%$ de Escoria, en peso \\
\hline $\begin{array}{l}\text { Cemento de horno alto } \\
\text { Cemento de hierro }\end{array}$ & $<35^{*}$ \\
\hline $\begin{array}{l}\text { Cemento portland de hierro } \\
\text { Cemento de horno alto }\end{array}$ & $35-80^{*}$ \\
Cemento de escoria de horno alto $35-60$ & $35-60^{*}$ \\
$60-80^{*}$
\end{tabular}


El Pliego de Condiciones para la recepción de Conglomerantes Hidráulicos, PCCH-64, (1) admite las dos clases de cementos siderúrgicos que se recogen en la tabla 2, según la cantidad de clínker, por una parte, y de escoria y sulfato cálcico, por otra, presentes en la mezcla.

TAB A A 2

\begin{tabular}{|c|c|c|}
\hline Clase & \% de Clínker, en peso & Escoria + Sulfato Cálcico, en peso \\
\hline Cemento siderúrgico & $\geqslant 70$ & resto \\
Cemento portland de horno alto & $30-70$ & resto \\
\hline
\end{tabular}

Las Prescripciones Técnicas Generales para la Recepción de Cementos, RC-75, (2) clasifican a los cementos siderúrgicos en las tres clases que se reseñan en la tabla 3, clasificación que es función de los contenidos respectivos de clínker más regulador de fraguado y de escoria siderúrgica.

T A в L A 3

\begin{tabular}{|c|c|c|}
\hline Clase & \% de Clínker + Regulador, en peso & \% de Escoria, en peso \\
\hline Siderúrgico I & $\geqslant 70 \mathrm{y}<80$ & $\leqslant 30 \mathrm{v}>20$ \\
Siderúrgico II & $\leqslant 50 \mathrm{y}<70$ & \\
Siderúrgico III & $>20 \mathrm{y}<50$ & $<80 \mathrm{v}>50$ \\
\hline
\end{tabular}

\section{CARACTERISTICAS DE LAS ESCORIAS}

\subsection{Generalidades}

Las escorias siderúrgicas están constituidas, fundamentalmente, por silicoaluminatos cálcicos y por otros compuestos que se encuentran en pequeña cantidad, entre los que destacan los siguientes: sulfuro cálcico, sulfuro de manganeso, óxidos de hierro y manganeso, hierro metálico; a veces pueden tener sílice libre (6). La composición de las escorias es función del producto fabricado, tipo de mineral utilizado, fundentes empleados, etc.

El desarrollo de la industria siderúrgica, en general, y de los procesos industriales (SM, Thomas, LD, LDAC) han afectado a la cantidad de escoria producida por tonelada de producto, factor decisivo del rendimiento de los hornos, y a su composición química.

Las escorias de horno alto, para poder emplearlas en la fabricación de cementos siderúrgicos deben cumplir una serie de requisitos que vienen fijados, principalmente, por su composición mineralógica, estado vítreo o cristalino, y química. Las conexiones entre la constitución de las escorias y las condiciones óptimas de obtención dentro del proceso siderúrgico (temperatura, viscosidad, capacidad de desulfuración, etc.) fueron ámpliamente tratadas en el Cuarto Symposium Internacional de la Química del Cemento, celebrado en Washington en el año 1960; conexiones que han sido estudiadas, posteriormente, por 
numerosos investigadores teniendo en consideración los diversos procesos de obtención de productos siderúrgicos, auxiliados por el desarrollo de las técnicas de control lo que ha permitido, además, obtener un mayor grado de uniformidad en dichos productos (7).

Las escorias de horno alto, enfriadas lentamente, están formadas por un conjunto de compuestos cristalinos, entre los que destaca la melilita, nombre aplicado a una serie de soluciones sólidas que comprende desde la akermanita $\left(2 \mathrm{CaO} \cdot \mathrm{MgO} .2 \mathrm{SiO}_{2}\right)$ a la gehlenita $\left(2 \mathrm{CaO} \cdot \mathrm{Al}_{2} \mathrm{O}_{3} \cdot \mathrm{SiO}_{2}\right)$. Por otra parte, se pueden presentar determinados minerales tales como la bredigita $\left(\alpha^{\prime}-2 \mathrm{CaO} . \mathrm{SiO}_{2}\right)$, larnita $\left(\beta-2 \mathrm{CaO} . \mathrm{SiO}_{2}\right)$, wollanstonita $\left(\mathrm{CaO}^{-\mathrm{SiO}_{2}}\right)$ y pseudo-

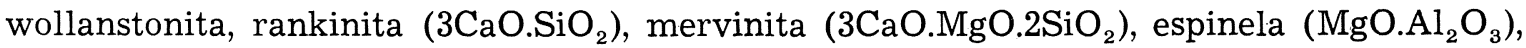
diópsido $\left(\mathrm{CaO} . \mathrm{MgO} .2 \mathrm{SiO}_{2}\right)$, monticellita $\left(\mathrm{CaO} . \mathrm{MgO} . \mathrm{SiO}_{2}\right)$, anortita $\left(\mathrm{CaO} \cdot \mathrm{Al}_{2} \mathrm{O}_{3} \cdot 2 \mathrm{SiO}_{2}\right)$, forsterita $\left(2 \mathrm{MgO} . \mathrm{SiO}_{2}\right)$, etc. (8) (9).

De todos los minerales mencionados los únicos que se hidratan a la temperatura y presión de vapor normales son $\alpha^{\prime}-2 \mathrm{CaO} . \mathrm{SiO}_{2}$ y $\beta-2 \mathrm{CaO} . \mathrm{SiO}_{2}$. El $\beta-2 \mathrm{CaO} . \mathrm{SiO}_{2}$ es metastable transformándose en la variedad $\gamma$; esta transformación puede tener lugar a la temperatura ambiente, produciendo un aumento de volumen, $\sim 10 \%$, que produce, cuando se encuentra en determinadas cantidades, la desintegración del mineral (9) (10). Los compuestos $\left(\alpha^{\prime}, \beta\right) 2 \mathrm{CaO} \mathrm{SiO}_{2}$ aparecen, por regla general, en las escorias que tienen un elevado contenido de $\mathrm{CaO}$; Parker y colaboradores han probado que el $2 \mathrm{CaO}^{-\mathrm{SiO}_{2}}$ puede no formarse cuando la relación entre los contenidos de $\mathrm{CaO}$ y $\mathrm{MgO}$ con relación a los de $\mathrm{SiO}_{2}$, $\mathrm{Al}_{2} \mathrm{O}_{3}$ y $\mathrm{S}$ se encuentran dentro de los límites especificados por las ecuaciones recogidas en la norma B. S. 1047:

$$
\begin{aligned}
& \mathrm{CaO} \leqslant 0,9 \mathrm{SiO}_{2}+0,6 \mathrm{Al}_{2} \mathrm{O}_{3}+1,75 \mathrm{~S} \\
& \mathrm{CaO}+0,8 \mathrm{MgO} \leqslant 1,2 \mathrm{SiO}_{2}+0,4 \mathrm{Al}_{2} \mathrm{O}_{3}+1,75 \mathrm{~S}
\end{aligned}
$$

ecuaciones que imponen criterios severos adoptados por otros países, de un modo especial por Francia, Alemania y Japón (9).

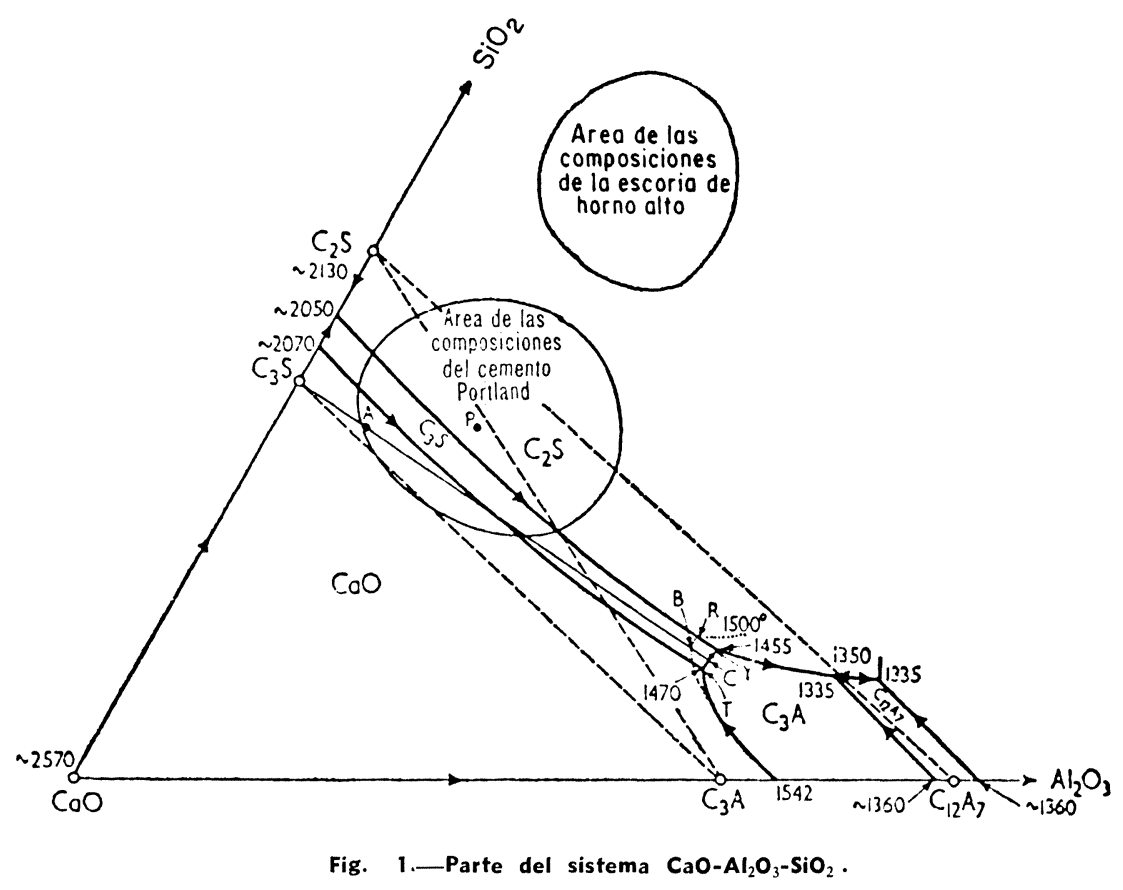

Según Lee (9) el hierro metálico que, a veces, contiene la escoria puede producir fenómenos expansivos por corrosión del mismo, que provocan la desintegración de la escoria; sumergiendo en agua, durante 14 días, una muestra de la escoria se pone de manifiesto dicho fenómeno. 
Los óxidos de hierro y manganeso cuando se presentan en pequeñas cantidades, $\sim 1 \%$, probablemente están en la solución sólida de uno de los otros minerales; por el contrario cuando se encuentran en cantidades mayores, $\sim 3 \%$, pueden aparecer en estado de sulfuros (8). La cantidad de sulfuros en la escoria, así como la de ésta en los cementos siderúrgicos, puede producir fenómenos perjudiciales debido a su inestabilidad (9) (11) (12).

En la figura 1 se ha representado la parte del diagrama del sistema ternario $\mathrm{CaO}-\mathrm{Al}_{2} \mathrm{O}_{3}$ $\mathrm{SiO}_{2}$ más importante para los minerales del clínker del cemento portland; diagrama que tiene como origen el de Rankin y Wright, modificado por los estudios de Osborn y Muam y por las revisiones posteriores efectuadas por otros investigadores, principalmente, en la región de la fase $\mathrm{C}_{3} \mathrm{~S}$ en la línea de coexistencia mullita-corindón y en la inclusión del campo de existencia del $\mathrm{CA}_{6}$ (13).

En la zona rica en $\mathrm{CaO}$ se encuentran los minerales del clínker del cemento portland y en sus proximidades los minerales de las escorias de horno alto (6).

La figura 2 (13) recoge las fases más importantes del sistema cuaternario CaO-MgO$\mathrm{Al}_{2} \mathrm{O}_{3}-\mathrm{SiO}_{2}$ en donde se incluyen los óxidos y las fases binarias y ternarias propias del clínker de cemento portland y de las escorias de horno alto; sistema que ha sido ampliamente estudiado tomando planos a niveles arbitrarios constantes de un constituyente, bien $\mathrm{Al}_{2} \mathrm{O}_{3}$ o MgO. Destacan los trabajos de Osborn y colaboradores para 5, 10, 15, 20, 25, 30 y $35 \%$ de $\mathrm{Al}_{2} \mathrm{O}_{3}$ y los de Mc. Murdie, Insley y Parker para el nivel de $5 \%$ de $\mathrm{MgO}$, Cavalier y Sandrea-Deudon para los niveles de 4 a $15 \%$ de $\mathrm{MgO}$, a intervalos de $1 \%$, y Prince para el nivel de $10 \%$ de $\mathrm{MgO}$, que tienen como objetivo principal delimitar las composiciones óptimas de las escorias de horno alto (13), composiciones que tienen que responder a la finalidad de dicha escoria (la zona líquida debe corresponder a bajas temperaturas, bajas viscosidades y tener gran poder de desulfuración) que se consigue normalmente con altas proporciones de los constituyentes básicos menores, que en el cemento portland. Se ha probado que dichas propiedades se obtienen con contenidos muy diferentes de $\mathrm{Al}_{2} \mathrm{O}_{3}$, existiendo valores óptimos de los otros constituyentes para un contenidos dado de $\mathrm{Al}_{2} \mathrm{O}_{3}$, así Farkas según Schröder (7), considera como óptimos los contenidos de MgO comprendidos entre 10 y $12 \%$.

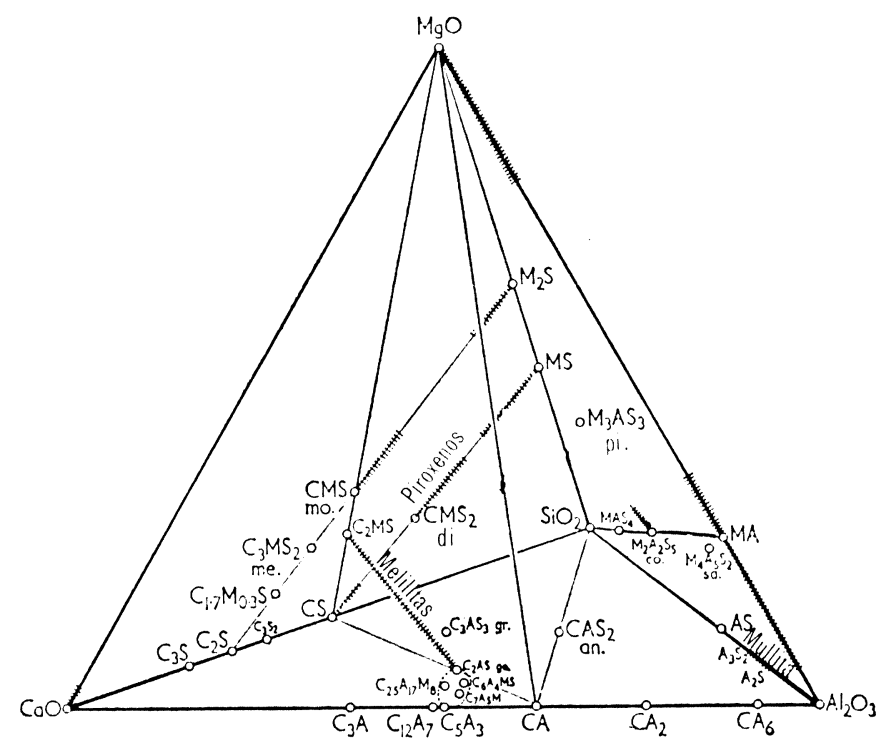

Fig. 2.-Fases del sistema $\mathrm{CaO}-\mathrm{MgO}-\mathrm{Al}_{2} \mathrm{O}_{3}-\mathrm{SiO}_{2}$.

Keil (14) señala que no existe periclasa en escorias vítreas con un contenido de $\mathrm{MgO}$ del orden del $15 \%$, encontrándose como espinela $\left(\mathrm{MgO}^{\mathrm{A}} \mathrm{Al}_{2} \mathrm{O}_{3}\right)$. 
Mc. Murdie e Insley (15) encontraron un punto invariable entre el líquido que contiene

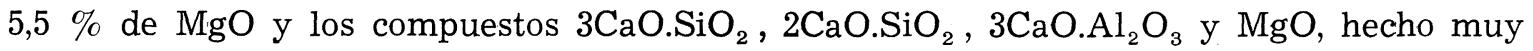
interesante para la fabricación de clínker de cemento portland; es posible que, si existe una cantidad mayor de $\mathrm{MgO}$, la periclasa se separe del fundido formando cristales que, durante la hidratación posterior, pueden producir fenómenos expansivos. Es interesante

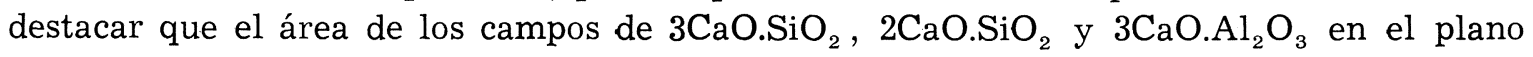
correspondiente al nivel de $5 \%$ de $\mathrm{MgO}$, según Parker, es análoga a la del sistema ternario $\mathrm{CaO}-\mathrm{Al}_{2} \mathrm{O}_{3}-\mathrm{SiO}_{2}$ ( $\sin \mathrm{MgO}$ ).

La magnesia se puede encontrar en las escorias cristalinas formando parte de silicatos y como espinela, compuestos ambos inofensivos; a veces se presenta como periclasa. La acción beneficiosa o perjudicial que ejerce la periclasa de la escoria en el hormigón es muy discutida; no obstante y como medida preventiva se limita su contenido en los cementos siderúrgicos.

En resumen, las escorias de horno alto tienen una composición química determinada para que puedan cumplir su función en el proceso siderúrgico, suministrando unos productos que presentan un estado cristalino o vítreo según el sistema de enfriamiento seguido y por tanto con propiedades químicas distintas, influyendo extraordinariamente para su aprovechamiento en el campo de la construcción.

Las escorias enfriadas al aire, que presentan las fases cristalinas mencionadas anteriormente, tienen pequeñas o nulas propiedades aglomerantes; sin embargo, la escoria enfriada rápidamente, escoria granulada, presenta un estado vítreo, en grado distinto, formando gránulos pequeños (8) segủn el proceso de enfriamiento utilizado. Las escorias granuladas, excepto las muy silícicas, tienen propiedades aglomerantes latentes que se ponen de manifiesto cuando se encuentran en presencia de un activador apropiado (cemento portland, cal, sulfato cálcico y cemento portland, hidróxido sódico o potásico, así como cualquier sal o mezcla de sales que en solución acuosa proporcionen un $\mathrm{pH}$ elevado); se trata, pues, de una propiedad fundamental para su empleo en la fabricación de cementos siderúrgicos o sobresulfatados.

A continuación se describen aquellas características más importantes de las escorias de horno alto para aplicarlas a su determinación cuali y cuantitativa en los cementos siderúrgicos.

\subsection{Composición química}

Las partículas de clínker de cemento portland están formadas por fases cristalinas, en gran proporción, y vítreas en cantidad apreciable, correspondiendo a compuestos cálcicos solubles en $\mathrm{HCl}$. La composición química oscila dentro de los límites que se señalan en la tabla 4.

Las partículas de escoria granulada, de estructura vítrea en gran proporción, están formadas también por compuestos cálcicos solubles en $\mathrm{HCl}$, respondiendo a la composición quỉmica que se señala en la tabla 5, cuyos límtes se incluyen en la tabla 4.

En la tabla 5 se recoge la composición química de muestras de escoria de diferentes países correspondientes al período de tiempo 1962-1967, tomada de Slags in Modern Blastfurnace Processes del Congreso Internacional de cemento celebrado en Tokyo en 1969 (16). Del mismo modo se incluyen los límites de la composición química de 28 muestras de escorias españolas correspondientes a la producción de los años 1974-1975. 
T A B L A 4

Límites de la composición química del cemento portland $y$ de escorias granuladas

\begin{tabular}{|c|c|c|}
\hline \multirow[b]{2}{*}{ Constituyente } & \multicolumn{2}{|c|}{$\%$, en peso } \\
\hline & Cemento portland & Escorias \\
\hline $\mathrm{SiO}_{2}$ & $19-23$ & $28-40$ \\
\hline $\mathrm{Al}_{2} \mathrm{O}_{3}+\mathrm{TiO}_{2}$ & $3-7$ & $5-23$ \\
\hline $\mathrm{FeO}$ & - & $0,2-3,8$ \\
\hline $\mathrm{Fe}_{2} \mathrm{O}_{3}$ & $1,4-4$ & $0,1-0,3$ \\
\hline $\mathrm{MnO}$ & - & $0,1-4,2$ \\
\hline $\mathrm{CaO}$ & $61-67$ & $28-48$ \\
\hline $\mathrm{MgO}$ & $0,6-3$ & $2-21$ \\
\hline $\mathrm{S}^{2-}$ & - & $0,4-2,2$ \\
\hline $\mathrm{SO}_{4}{ }^{2-}$ (expresados como SO:) & $1,5-4$ & - \\
\hline $\mathrm{Na}_{2} \mathrm{O}+\mathrm{K}_{2} \mathrm{O}$ & $0,3-1,5$ & $0,7-3,6$ \\
\hline
\end{tabular}

T A B L A 5

Límites de composición química de escorias, \% en peso

\begin{tabular}{|c|c|c|c|c|c|c|c|c|}
\hline \multirow{2}{*}{ Constituyente } & \multicolumn{7}{|c|}{ Muestras de 1962-1967 } & \multirow{2}{*}{\begin{tabular}{|l}
$1974-75$ \\
España
\end{tabular}} \\
\hline & Ruhrgebelí & Niedersachsen & Saargebiet & Francia & Inglaterra & Rusia & Sud-Africa & \\
\hline $\mathrm{SiO}_{2}$ & $28-40$ & $34-39$ & $34-35$ & $30-38$ & $32-40$ & $34-35$ & $28-36$ & $31-38$ \\
\hline $\mathrm{Al}_{2} \mathrm{O}_{3}$ & $10-18$ & $12-16$ & $13-16$ & $13-22$ & $14-22$ & $5-23$ & $12-22$ & $12-26$ \\
\hline $\mathrm{FeO}$ & $0,2-2,1$ & $0,3-1,2$ & $0,4-2,0$ & $0,5-3,8$ & $0,3-1,2$ & $0,3-2,4$ & $0,6-2,5$ & $0,5-1,2^{*}$ \\
\hline $\mathrm{MnO}$ & $0,1-4,2$ & $0,9-2,0$ & $0,5-1,1$ & $0,1-1,0$ & $0,1-2,6$ & $0,1-2,1$ & $0,2-0,9$ & $0,6-1,6$ \\
\hline $\mathrm{TiO}_{2}$ & $0,1-1,5$ & 0,5 & $0,5-1,1$ & 0,5 & $0,4-1,0$ & - & - & $0,2-0,5$ \\
\hline $\mathrm{CaO}$ & $38-46$ & $32-42$ & $37-43$ & $35-48$ & $33-43$ & $29-48$ & $28-36$ & $29-40$ \\
\hline $\mathrm{MgO}$ & $5-12$ & $5-10$ & $4-8$ & $2-8$ & $2-16$ & $0-18$ & $13-21$ & $5-10$ \\
\hline $\mathrm{Na}_{2} \mathrm{O}$ & $0,4-2,3$ & $1,1-1,2$ & $0,4-1,0$ & $0,3-0,5$ & $0,3-05 *$ & - & - & 0,9 \\
\hline $\mathrm{K}_{2} \mathrm{O}$ & $0,3-1,3$ & $1,3-1,5$ & $0 ; 6-0,8$ & $0,6-0,8$ & $0,4-1,4$ & - & - & $0,7-1,3$ \\
\hline S & $0,9-2,2$ & $0,7-1,0$ & $0,6-1,0$ & $0,4-1,5$ & $0,7-2,7$ & 1,1 & $0,7-1,4$ & $1,2-1,5$ \\
\hline
\end{tabular}

* Como $\mathrm{Fe}_{2} \mathrm{O}_{3}$ de 0,1 a $1,1 \%$.

Examinando los valores correspondientes a la composición química del cemento y de las escorias puede observarse que:

a) Las escorias siderúrgicas tienen compuestos que presentan propiedades reductoras; compuestos que, prácticamente, no existen en los clínkeres normalmente fabricados. A veces aparecen en pequeña cantidad, menor que en las escorias, sobre todo en los clínkeres obtenidos en hornos verticales.

b) Las escorias tienen determinados compuestos como son los sulfuros solubles en ácidos minerales que no existen en los clínkeres normalmente fabricados, por lo que desprenderán $\mathrm{H}_{2} \mathrm{~S}$, fácilmente detectable, cuando se tratan con ácidos minerales.

Además presentan otros elementos minoritarios, p.e. manganeso (II), hierro (II), etc., formando compuestos que en las escorias se encuentran en mayor cantidad.

$\because$ Debe decir: $0,3-0,5$ 
c) El contenido de $\mathrm{SiO}_{2}(28-40 \%), \mathrm{Al}_{2} \mathrm{O}_{3}$ y $\mathrm{TiO}_{2}(5,23 \%)$ y $\mathrm{MgO}(2-21 \%)$ de las escorias es mayor que el del cemento portland (19-23\%, 3-7 \% y 0,6-3\%, respectivamente); sin embargo, el contenido de $\mathrm{CaO}(28-48 \%)$ y de $\mathrm{SO}_{3}$ (hasta $1 \%$ ) es menor (61-67 \% y 1,5-4 \%, respectivamente), hechos que se aplican para determinar cualitativa y cuantitativamente la presencia y el contenido de escorias en los cementos siderúrgicos.

\subsection{Solubilidad de las escorias}

Dada la composición de los componentes del clínker y de la escoria granulada presentan, ambos, un comportamiento análogo frente a determinados reactivos químicos y diferencial en ciertos casos; comportamiento que se debe tener en consideración por su posible aplicación al control de calidad o de producción de los cementos siderúrgicos.

Tanto las escorias siderúrgicas como el clínker de cemento portland son solubles en ácidos minerales, p.e. $\mathrm{HCl}$, dejando un residuo insoluble que suele ser prácticamente despreciable; en el caso del clínker es menor de 0,5\%. Esta propiedad se aplica a la determinación cuantitativa de adiciones activas presentes en el cemento portland, como son las cenizas volantes y las puzolanas, que tienen residuos insolubles en $\mathrm{HCl}$ diluido de consideración.

Musikas (17) determina el contenido de cenizas volantes en cementos franceses comerciales por medio de esta técnica, confirmando la eficacia del ataque por examen de los residuos insolubles con una lupa binocular; en la fracción fina de dichos residuos, examinados por espectrometría IR, no se han detectado las bandas correspondientes a las fases mineralógicas presentes habitualmente en el clínker.

Los silicatos bicálcicos y tricálcicos $\left(\mathrm{C}_{2} \mathrm{~S}, \mathrm{C}_{3} \mathrm{~S}\right)$ de los granos del clínker son atacados por ácido salicílico en medio alcohólico (metanol) (18), así como la cal libre y el hidróxido cal= cico; sin embargo, solamente una pequeña parte de la escoria es soluble, $5 \pm 2 \%$ según Musikas, lo que limita su aplicación a determinados casos.

Los componentes cálcicos del clínker y de la escoria son atacados en grado distinto por una disolución acuosa de $\mathrm{NH}_{4} \mathrm{Cl}$, dejando en la disolución una cantidad de $\mathrm{Ca}$ (II) distinta para cada mezcla clínker-escoria.

El clínker de cemento portland es más soluble que la escoria en una disolución alcohólica de ácido acético; trabajando en las condiciones adecuadas se puede obtener el contenido de escorias en los cementos siderúrgicos con una precisión, según Hart, Grigorieff y Chaikina, de $\pm 1 \%$ (19).

Keil y Gille (20) han estudiado los mecanismos que tienen lugar en el ataque de escorias con acetato o nitrato amónico, acetato o citrato de metilamina, acetato o citrato de acetilamina, acetato o citrato de dimetilamina.

\subsection{Peso específico del clínker, de la escoria y del yeso}

El peso específico medio de los tres componentes de los cementos siderúrgicos es el siguiente:

Clínker de cemento portland: $3,15 \mathrm{~g} / \mathrm{cm}^{3}$, según Musikas y $3,07 \mathrm{~g} / \mathrm{cm}^{3}$, según Venuat.

Escoria granulada:

$2,90 \mathrm{~g} / \mathrm{cm}^{3}$, según Musikas y 2,85 g/ $\mathrm{cm}^{3}$, según Venuat.

Yeso:

$2,30 \mathrm{~g} / \mathrm{cm}^{3}$, según Musikas. 
Las pequeñas diferencias que existen en el peso específico dan un margen suficiente pàra poder separar por líquidos densos los componentes de la mezcla (cemento siderúrgico), como se verá más adeìante.

\subsection{Características mineralógicas}

\section{Clínker de cemento portland}

El clínker es un compuesto que presenta una gran proporción de fase cristalina y en determinados casos, una apreciable cantidad de fase vítrea; los granos de clínker son, por consiguiente, opacos a la luz transmitida en gran parte, mostrando un contorno irregularmente redondeado o anguloso.

El índice de refracción es, según Lea (8), aproximadamente 1,70.

\section{Escoria granulada}

Los granos de escoria granulada, de estructura vítrea, son transparentes a la luz transmitida e isotrópicos, presentando un contorno anguloso y una fractura neta. La escoria básica se caracteriza porque sus granos, en la mayoría de los casos, tienen bordes redondeados y aspecto de gravilla rodada, mientras que los granos de escoria ácida tienen los bordes astillados o concoideos; a menudo encierran burbujas de aire.

Ciertos granos de escoria granulada están coloreados de amarillo y aun de violeta por la presencia de compuestos de hierro y de manganeso; muestran cavidades semicirculares, inclusiones globulares o dendríticas y puntos negros y grises.

El índice de refracción de los vidrios de escoria varía desde 1,635 a 1,67; el índice de refracción de las escorias ricas en cal es superior a 1,65 (8).

\section{Yeso}

Los granos de yeso son laminares, blancos, más o menos traslúcidos, según la finura, y de contorno poligonal; presentan gran analogía con los granos de escoria.

\subsection{Actividad potencial de las escorias granuladas}

Las escorias granuladas de estructura vítrea presentan unas características propias de dicha estructura, quę se utilizan, en gran parte, para determinar la actividad de las mismas con objeto de poderlas emplear en la fabricación de cementos siderúrgicos.

La actividad potencial hidráulica latente de las escorias granuladas se determina por diversos procedimientos químicos, fisicoquímicos o tecnológicos, entre los que cabe destacar: la composición química (módulos o índices recogidos en distintas normas); la capacidad de reacción con una disolución de hidróxido sódico, con los productos resultantes de la hidratación del clínker de cemento portland, cal hidratada, yeso; la velocidad de reacción con una disolución de sulfato de aluminio; el calor de disolución; el desprendimiento de energía térmica cuando se someten a la acción creciente del calor (ensayo de recalescencia, ATD); los espectros de difracción de rayos $\mathrm{X}$; el comportamiento frente a la luz transmitida (examen microscópico), a la radiación ultravioleta; la coloración con azul de metileno; la facilidad de molienda; la aptitud de granulación; la capacidad de retención de agua, etc. (21). 


\section{DETERMINACION DEL CONTENIDO DE ESCORIAS EN LOS CEMENTOS SIDERURGICOS}

La determinación del contenido de escorias en los cementos siderúrgicos es un problema de gran importancia no sólo para el fabricante, sino para el usuario de dichos cementos.

Los cementos siderúrgicos son mezclas de los tres componentes mencionados en el apartado 1: clínker de cemento portland, escoria granulada y yeso, regulador de fraguado, en proporciones distintas; conviene tener en consideración que existe, además, una fracción magnética.

Como es sabido las características químicas, físicas y mecánicas de los cementos siderúrgicos son función, fundamentalmente, de la composición y de las características mineralógicas de los componentes.

\subsection{Determinación cualitativa}

Teniendo en cuenta las características específicas de los componentes de los cementos siderúrgicos, diferentes de unos a otros, bien sean químicas, físicas o mineralógicas se pueden utilizar diversas técnicas de trabajo simples para determinar la presencia de escoria en los cementos, dentro de ellas cabe destacar las que se señalan a continuación.

\subsubsection{Técnicas químicas}

Las técnicas químicas que normalmente se usan para determinar cualitativamente la presencia de escoria en los cementos se basan en la existencia de sulfuros y compuestos reductores en las escorias; compuestos que no se encuentran en el clínker normalmente fabricado y, caso de existir, es en pequeña cantidad.

\section{a) Identificación de sulfuros}

La presencia de escoria, aun en pequeña cantidad, se pone de manifiesto por el desprendimiento de sulfuro de hidrógeno $\left(\mathrm{H}_{2} \mathrm{~S}\right)$ que tiene lugar cuando el cemento se trata con una disolución acuosa de $\mathrm{HCl}$ diluido, gas fácilmente reconocible por su olor o por la coloración negra de $\mathrm{PbS}$, que se produce cuando los gases desprendidos se ponen en contacto con un papel de filtro humedecido con una disolución de plumbito sódico o acetato de plomo (22) (23) (24) y otros.

b) Reacción de reductores

La presencia de compuestos reductores (aniones o cationes) se pone de manifiesto por la decoloración en frío o en caliente que experimenta una disolución diluida de $\mathrm{KMnO}_{4}$, en medio ácido (25) (26) y otros.

\subsubsection{Técnicas fisicoquímicas}

Las técnicas fisicoquímicas que se utilizan para determinar la presencia de escorias en los cementos se basan en las distintas características mineralógicas o estructurales de los componentes de la mezcla, descritas en los apartados anteriores; dentro de estas técnicas cabe citar las siguientes: 

a) Examen microscópico
(27)
(28) $(29)$
$(30)(50)$

Los granos de escoria granulada son transparentes en su mayoría a la luz transmitida, mientras que los de clínker son opacos en gran parte; ambos tienen una forma característica y distinta. Los granos de yeso presentan gran analogía con los de escoria, aun cuando son de forma laminar; basta la acción del reactivo de Gonell ( 2 partes de una disolución acuosa de acetato de plomo al $5 \%$ y una parte de una disolución acuosa de ácido acético al $50 \%$ ) para que los granos de escoria se cubran de $\mathrm{PbS}$, negro, mientras que los de yeso permanecen incoloros y los de clínker con su coloración.

El examen microscópico se puede realizar con un microscopio corriente o con una lupa binocular.

Haciendo uso del distinto índice de refracción de los granos de escoria $(1,65-1,66)$ y de clínker $(1,70)$ se puede determinar fácilmente la presencia de escoria; del mismo modo se pueden diferenciar los granos de escoria y de yeso examinándolos con luz polarizada, ya que los granos no vítreos son birrefringentes.

b) Examen con luz ultravioleta (21) (31)

Las escorias granuladas experimentan el fenómeno de luminiscencia, ligado a su estado vítreo, cuando se someten a la acción de radiaciones de corta longitud de onda, rayos ultravioletas, fenómeno que no presentan los granos de clínker.

\section{c) Reacción con azul de metileno (21) (32)}

Los productos resultantes de la reacción de una disolución de hidróxido potásico con las escorias, posiblemente con los silicatos cálcicos y el magma silíceo de las escorias vítreas, se caracterizan por adsorber el colorante azul de metileno. Las escorias menos hidráulicas se colorean mucho más débilmente que las más ricas en fase vítrea.

\subsubsection{Técnicas físicas}

En el grupo de técnicas físicas hemos incluido únicamente la que se apoya en el distinto peso específico de cada uno de los componentes de la mezcla (apartado 2.4.), lo que permite separar cada una de las fracciones, identificarlas cualitativamente y determinarlas cuantitativamente; para ello se utilzan líquidos densos apropiados (apartado 3.2.3.). $\mathrm{La}$ fracción correspondiente a la escoria se confirma, bien por tratamiento con $\mathrm{HCl}$ diluido o bien por examen microscópico.

\subsection{Determinación cuantitativa}

En el apartado anterior se ha visto que la determinación cualitativa de escoria en los cementos no ofrece dificultades, hecho que no sucede con la determinación cuantitativa, teniendo que hacer uso, en la mayoría de los casos, de más de una técnica de trabajo de tipo químico, fisicoquímico y/o físico, para obtener resultados que ofrezcan un grado aceptable de fiabilidad.

La determinación cuantitativa se simplifica cuando se dispone de los componentes puros de la mezcla, de un modo especial clínker y escoria. Cuando no se dispone de dichos componentes, no son fiables o se quiere comprobar su identiad, se impone la separación de los mismos en el cemento; la pequeña diferencia que existe en los pesos específicos 
es suficiente para que utilizando líquidos densos apropiados se puedan conseguir las fracciones puras. Otro problema planteado resuelto favorablemente, es utilizar una fracción granulométrica del cemento representativa del conjunto que facilite las diversas operaciones y proporcione resultados exactos y precisos; esta fracción es la comprendida entre 100 y $200 \mu$ (41), 88 у $120 \mu(30), 60$ у $88 \mu$ (30) (33), 50 у $70 \mu$ (34), 50 у $63 \mu$ (35), $30-40 \mu$ у $30-63 \mu(51)$ у 30 а 40 у $80 \mu$.

\subsubsection{Aplicación de técnicas químicas}

La cantidad de escorias en los cementos siderúrgicos se puede determinar a partir del contenido de los elementos mayoritarios de la escoria, del clínker y del cemento; del contenido de un elemento trazador o guía específico de la escoria, como pueden ser los sulfuros, compuestos de manganeso, compuestos reductores, etc.; por determinación del calcio (II) cedido por el clínker y por la escoria en una disolución de $\mathrm{NH}_{4} \mathrm{Cl}$; por determinación del contenido de clínker y de yeso del conglomerante, etc. De aquí que consideremos, en el presente apartado, los casos que se señalan a continuación, según que se determine la composición química, el poder reductor o un elemento trazador o guía del cemento, escoria y/o clínker, la cantidad de calcio (II) cedida por el clínker y por la escoria en una disolución de $\mathrm{NH}_{4} \mathrm{Cl}$ y la cantidad de clínker presente por ataque selectivo.

\section{a) Determinación por análisis químico}

El análisis químico de los cementos siderúrgicos no sólo pone de manifiesto la presencia de escorias sino la proporción en que entran a formar parte de los mismos. La determinación cuantitativa se facilita y simplifica cuando se dispone de muestras representativas de los componentes de la mezcla, imponiéndose la separación, como se ha mencionado, cuando no se dispone de ellos, cuando no son fiables o cuando se quiere confirmar su identidad.

La determinación de la cantidad de escoria en los cementos siderúrgicos se puede realizar conociendo el contenido de los constituyentes mayoritarios (expresados como óxidos: $\mathrm{CaO}, \mathrm{Al}_{2} \mathrm{O}_{3}$ y $\mathrm{SiO}_{2}$ ) que tienen los componentes, escoria y clínker, del cemento objeto de estudio. A veces se utiliza como constituyente trazador o guía uno de ellos $(\mathrm{CaO})$ (36); Schröder y Vinkeloe (37) señalan como constituyentes guía los óxidos de calcio o de manganeso $(\mathrm{CaO}$ o $\mathrm{MnO})$.

Duriez y Houlnick (38) describen un método en virtud del cual por determinación de la composición química de diversas mezclas de clínker-escoria, del clínker y de la escoria, calculan el contenido de escoria por un método gráfico o por un cálculo simple. El método gráfico consiste en lo siguiente: los resultados obtenidos correspondientes a $\mathrm{CaO}, \mathrm{SiO}_{2}$ y $\mathrm{Al}_{2} \mathrm{O}_{3}$ de la escoria y del clínker se llevan a dos ejes verticales separados por una escala horizontal que representa el \%, en peso, de clínker y de escoria del cemento, uniendo por medio de una recta (A) los puntos representativos de dichos óxidos. Los valores experimentales de $\mathrm{CaO}, \mathrm{SiO}_{2}$ y $\mathrm{Al}_{2} \mathrm{O}_{3}$ del cemento se llevan a la correspondiente recta (A) que proporciona directamente la mezcla clínker-escoria.

El contenido de escoria se puede determinar por la expresión:

$$
\% \text { escoria }=\frac{c-k}{e-k} \cdot 100
$$

en donde $c$ es el $\%$, en peso, del constituyente trazador o guía en el cemento, $e$ en la escoria y $k$ en el clínker. 


\section{b) Determinación del poder reductor}

Con el nombre de poder reductor se conoce en los cementos siderúrgicos el número de $\mathrm{ml}$ consumidos de una disolución acuosa $0,1 \mathrm{~N}$ de $\mathrm{KMnO}_{4}$ al reaccionar con los compuestos reductores de la muestra $(1 \mathrm{~g})$ de escoria, de clínker o del cemento objeto de estudio. El poder reductor es, por consiguiente, proporcional al número de $\mathrm{ml}$ consumidos de dicha disolución de $\mathrm{KMnO}_{4}$.

Las escorias tienen compuestos con propiedades reductoras, fundamentalmente sulfuros y compuestos ferrosos, compuestos que no existen en el clínker normalmente fabricado, como hemos dicho antes, salvo casos excepcionales como sucede con el fabricado en hornos verticales, o si existen es en pequeña cantidad, por lo que es recomendable determinar el poder reductor del clínker base del cemento siderúrgico. La mayoría de los clínkeres de cemento portland tienen un poder reductor comprendido entre 0,4 y 2,5 mientras que el de las escorias oscila de 18 a 26 (33).

Se ha de tener en cuenta que en el cemento, clínker y escoria existen, en la mayoría de los casos, partículas metálicas que, una vez llevadas a disolución, pueden presentar propiedades reductoras por lo que se deben eliminar previamente con un imán.

Janssens (33), apoyándose en los trabajos de McCoy (39) y de Killig (40), determina el contenido de escoria en los cementos metalúrgicos haciendo uso del poder reductor del cemento y de sus componentes, escoria y clínker, con los que ha sido fabricado; para ello adiciona un exceso de una disolución $0,1 \mathrm{~N}$ de $\mathrm{KMnO}_{4}$ que oxida, en medio $\mathrm{H}_{2} \mathrm{SO}_{4}$ fuerte, a los compuestos reductores presentes en los componentes, de un modo especial en la escoria, y en el cemento. El exceso de la disolución de $\mathrm{KMnO}_{4}$ se determina por una volumetría redox por retroceso utilizando como reductor una disolución acuosa $0,1 \mathrm{~N}$ de oxalato sódico; la cantidad de la disolución de oxalato que no ha reaccionado se valora con la disolución $0,1 \mathrm{~N}$ de $\mathrm{KMnO}_{4}$.

Conocido el poder reductor (P.R.) de la escoria, del clínker y del cemento, el contenido de escoria se calcula por medio de la expresión:

$$
\% \text { de escoria }=\frac{P . R .(\text { cemento })-P . R .(\text { clínker })}{P . R .(\text { escoria })-P . R .(\text { clínker })} \cdot 100
$$

\section{c) Determinación del contenido de sulfuros}

Musikas (35) haciendo uso de la técnica de separación de los componentes del cemento por líquidos densos y de la determinación de sulfuros por el método clásico aplicado al caso de cementos (1) (4), describe un procedimiento operatorio que ha utilizado con buenos resultados en mezclas sintéticas y en cementos comerciales.

La escoria pura presente en el cemento siderúrgico se obtiene a partir de la fracción granulométrica comprendida entre 50 y $63 \mu$, eliminando de este modo la coagulación que experimentan las partículas más finas (8).

Musikas ha demostrado que dicha fracción es representativa del conjunto del cemento, sin separar ninguna fracción, así como de las fracciones menores de $50 \mu$ y mayores de $63 \mu$, llegando a la conclusión de que los sulfuros se encuentran repartidos uniformemente en la escoria y, por consiguiente, en las distintas fracciones.

La separación de los componentes de la fracción mencionado del cemento, objeto de estudio, se hace con líquidos densos que tienen un p.e. de 3,00 y $2,70 \mathrm{~g} / \mathrm{cm}^{3} \mathrm{con}$ los que consigue separar la fracción clínker (p.e. medio $=3,15 \mathrm{~g} / \mathrm{cm}^{3}$ ) de la fracción escoria (p.e. medio $=2,90 \mathrm{~g} / \mathrm{cm}^{3}$ ) y de la fracción yeso (p.e. medio $=2,30 \mathrm{~g} / \mathrm{cm}^{3}$ ) y la fracción escoria de la fracción yeso, centrifugando, para ello, la mezcla con los dos líquidos densos mencionados. 
Los dos líquidos densos utilizados se preparan a partir de yoduro de metileno (p.e. $=3,31$ $\mathrm{g} / \mathrm{cm}^{3}$ ) y de o-xileno (p.e. $=0,86 \mathrm{~g} / \mathrm{cm}^{3}$ ), mezclando $10 \mathrm{ml}$ de yoduro de metileno y 1,5 $\mathrm{ml}$ de o-xileno para el primero (p.e. $=3,00 \mathrm{~g} / \mathrm{cm}^{3}$ ) y $10 \mathrm{ml}$ de esta disolución con $1,4 \mathrm{ml}$ de o-xileno para el segundo (p.e. $=2,70 \mathrm{~g} / \mathrm{cm}^{3}$ ).

La fracción ferromagnética queda en la fracción clínker, por lo que se recomienda separarla previamente del cemento.

El contenido de sulfuros se determina en la fracción escoria pura y en el cemento por el método de evolución; para ello se ataca la muestra con una disolución acuosa de $\mathrm{HCl}$ diluido que solubiliza a los sulfuros, desprendiéndose el $\mathrm{H}_{2} \mathrm{~S}$ formado, el cual se recoge en una disolución de acetato de cinc $(20 \mathrm{~g} / l)$ y acetato de cadmio $(2 \mathrm{~g} / l)$ en donde precipita el correspondiente sulfuro de cinc $(\mathrm{ZnS})$. A continuación se determina el ion sulfuro yodimétricamente.

La escoria presente se calcula por medio de la siguiente expresión:

$$
\% \text { escoria }=\frac{\% \mathrm{~S}^{2-}}{\% \mathrm{~S}^{2-}} \frac{\text { (cemento })}{(\text { escoria })} \cdot 100
$$

\section{d) Determinación del contenido de compuestos de manganeso (II)}

García de Paredes (4) recoge el método de Catharin (41) que consiste en determinar el contenido de compuestos de manganeso en los componentes clínker y escoria, obtenidos de la fracción de cemento comprendida entre 100 y $200 \mu$ por separación con líquidos densos, y en el conglomerante.

La determinación se realiza por transformación de los compuestos de manganeso (II) en $\mathrm{MnO}_{4}^{-}$utilizando como agente oxidante una disolución de persulfato amónico en medio nítrico y en presencia de $\mathrm{Ag}$ (I), procedente de una disolución de $\mathrm{AgNO}_{3}$, que actúa como catalizador (42). El permanganato formado se valora con una disolución patrón de arsenito sódico expresando el resultado en \%, en peso, de $\mathrm{MnO}$ (elemento trazador o guía).

El hierro se separa, previamente, del conjunto con objeto de evitar las interferencias y, por consiguiente, las correcciones que se deberían establecer en el conjunto y en cada uno de los componentes. Catharin efectúa la separación únicamente en la fracción clínker y considera que en la escoria existe el $1 \%$. La escoria presente se determina por un cálculo simple:

$$
\% \text { escoria }=\frac{\% \mathrm{MnO}(\text { cemento })-\% \mathrm{MnO} \text { (clínker) }}{99 / 100 \% \mathrm{MnO}(\text { escoria })-\% \mathrm{MnO} \text { (clínker) }} \cdot 100
$$

si se separa la fracción magnética únicamente en el clínker, y por medio de la expresión:

$$
\% \text { escoria }=\frac{\% \mathrm{MnO}(\text { cemento })-\% \mathrm{MnO} \text { (clínker) }}{\% \mathrm{MnO} \text { (escoria) }-\% \mathrm{MnO} \text { (clínker) }} \cdot 100
$$

Si se separa previamente en el conjunto, no existiendo por consiguiente en el cemento, ni en las fracciones escoria y clínker.

Los líquidos densos que se utilizan son mezclas a base de bromoformo y yoduro de metileno para preparar líquidos que tengan como p.e. $2,90,2,98$ y $2,30 \mathrm{~g} / \mathrm{cm}^{3}$ con los que se pueden obtener las fracciones de escoria y de clínker puros. 
e) Determinación del calcio (II) cedido a una disolución de cloruro amónico por el clínker y por la escoria

Hayden (43) expone el comportamiento distinto que presentan las escorias, el clínker e incluso el crudo de cemento portland cuando se someten a la acción de disoluciones acuosas de sales amónicas a la temperatura de ebullición; comportamiento que lleva consigo una cesión de $\mathrm{Ca}$ (II) a la disolución, un incremento de $\mathrm{pH}$ y una liberación de $\mathrm{NH}_{3}$ que se determina por el método de Kjeldahl (44).

El cálculo del contenido de escorias se puede realizar por un procedimiento gráfico (45), recogido por García de Paredes (4). En dos ejes verticales, separados por una escala horizontal que representa el \% de escoria, se llevan los $\mathrm{ml}$ de $\mathrm{HCl}, \mathrm{N} / 2$ consumidos en la valoración de la basicidad de la disolución de amoniaco, correspondientes a $1 \mathrm{~g}$ de clínker y a $1 \mathrm{~g}$ de escoria, que se unen por una recta; el valor experimental se lleva a la recta mencionada la cual proporciona la relación clínker-escoria.

\section{f) Otros procedimientos}

En el presente apartado se incluye un procedimiento indirecto que permite conocer la cantidad de escoria presente en los cementos siderúrgicos, determinando la cantidad de clínker y yeso, procedimiento que, por otra parte, se puede aplicar para determinar los dos componentes activos, p.e. escorias y cenizas volantes, en los cementos ternarios.

- Determinación del contenido de clínker por ataque químico selectivo

Musikas (35) describe un método para determinar el contenido de clínker en un cemento que tenga adiciones activas, escorias y/o cenizas volantes, basado en el ataque selectivo del ácido salicílico en medio alcohólico (metanol) sobre los silicatos cálcicos del clínker, puro o presente en el cemento, método de Takashima (18) y en la presencia de un elemento trazador o guía en dichos silicatos que se pueda determinar cuantitativamente.

El elemento guía elegido es el Fe (III) que se encuentra en los silicatos sustituyendo al silicio (35) o formando una solución sólida (46), el cual da una coloración roja con el ácido salicílico en las condiciones en que se efectúa el ataque. Las disoluciones de ácido salicílico dan con $\mathrm{FeCl}_{3}$ un intenso color rojo violeta (47), púrpura (48) o violeta en disolución alcohólica (49).

La absorción luminosa del líquido coloreado a $490 \mathrm{~nm}$ es directamente proporcional al contenido de hierro disuelto y por consiguiente de clínker. La relación de las absorciones luminosas o de las densidades ópticas, por gramo de muestra, correspondientes a la disolución, una vez atacado el cemento y el clínker puro, obtenido a partir de dicho cemento, proporciona directamente el contenido de clínker en la mezcla.

El clínker puro se obtiene a partir del cemento del que se han separado previamente los compuestos ferromagnéticos, por centrifugación de la fracción granulométrica comprendida entre 50 y $63 \mu$ utilizando, para ello, una mezcla de $1,5 \mathrm{ml}$ de o-xileno y $10 \mathrm{ml}$ de yoduro de metileno (p.e. $=3,00 \mathrm{~g} / \mathrm{cm}^{3}$ ). Del mismo modo se han de separar previamente los compuestos ferromagnéticos del cemento que se va a utilizar en el ataque químico selectivo.

Las escorias son ligeramente solubles en ácido salicílico-metanol, $5 \pm 2 \%$, solubilidad que introduce un ligero error sistemático sobre el contenido de clínker que llega a ser de consideración en los cementos que tienen un elevado contenido de escoria (superior a $30 \%$ ); en este caso es mejor obtener el contenido de clínker por cálculo conociendo el contenido de escoria y de yeso, determinados experimentalmente. 
Cuando la adición activa al cemento es ceniza volante la determinación del clínker va afectada de un error relativo menor de $1,3 \%$.

- Determinación del contenido de yeso

El contenido de yeso del cemento se determina por vía química (gravimetría del $\mathrm{BaSO}_{4}$, técnica usada normalmente para determinar el contenido de sulfatos) a partir del contenido de sulfatos tanto del clínker y de las escorias, separados de la mezcla, como del cemento objeto de estudio.

El clínker de cemento portland contiene siempre una cantidad apreciable de sulfatos; el valor medio es del orden de $0,5 \%$, expresados como $\mathrm{SO}_{3}$.

- Determinación de los componentes secundarios, escorias y cenizas volantes, en los cementos ternarios

A continuación se recoge un procedimiento propuestos por Musikas (35) que, en síntesis, es una aplicación de distintos métodos, descritos anteriormente, para conocer el contenido de clínker y el de escorias por ataque químico diferencial con ácido salicílico-metanol y determinación de la densidad óptima," el primero, y por valoración del contenido de sulfuros el segundo. Como es lógico hay que hacer las determinaciones correspondientes en el cemento; la fracción granulométrica de cemento que se utiliza para separar los componentes por sedimentación en líquidos densos es la comprendida entre 50 y $63 \mu$. Previamente se debe separar la fracción ferromagnética del cemento.

El contenido aproximado de clínker en los cementos ternarios incluidos en este apartado se puede conocer, además, determinando el residuo insoluble en ácido salicílico-metanol del cemento y del clínker separado de la mezcla.

El contenido de cenizas volantes se determina bien por cálculo, para ello basta con conocer los de clínker, escoria y yeso, o bien por vía química a partir del residuo insoluble en $\mathrm{HCl}$ diluido del cemento y de la escoria. En este caso se debe conocer el residuo insoluble de las cenizas volantes.

En casos análogos al presente es conveniente confirmar la eficacia del ataque, tanto con ácido salicílico-metanol como con $\mathrm{HCl}$ diluido para asegurar, en el primer caso, que los silicatos cálcicos se han disuelto cuantitativamente y en el segundo que los granos de clínker también se han disuelto cuantitativamente. Esta confirmación se puede realizar por examen microscópico de los residuos en $\mathrm{HCl}$ o por estudio de los espectros infrarrojos de la fracción fina de los residuos tanto en $\mathrm{HCl}$ como en ácido salicílico-metanol.

\subsubsection{Aplicación de técnicas fisicoquímicas}

- Determinación del contenido de escorias por recuento microscópico

El contenido de escorias en los cementos siderúrgicos se puede determinar por recuento microscópico de las partículas de clínker, de escoria y/o de yeso, que se encuentran en una fracción granulométrica del cemento objeto de estudio.

Las características mineralógicas específicas del clínker, de la escoria granulada y del yeso permiten diferenciarlos fácilmente por examen microscópico (20) (27) (28) (29) (30) (34) (35) (50) o por examen con una lupa binocular (35).

Los granos de clínker son opacos a la luz transmitida, en gran parte, presentando un contorno irregularmente redondeado o anguloso.

* Debe decir: óptica 
Los granos de escoria granulada son transparentes a la luz transmitida e isotrópicos, mostrando un contorno anguloso y de fractura neta; los granos de escoria básica tienen, en la mayoría de los casos, bordes redondeados y aspecto de gravilla rodada, mientras que los de escoria ácida tienen bordes astillados o concoideos y a veces burbujas de aire. Determinados granos están coloreados de amarillo o de violeta por la presencia de compuestos de hierro y de manganeso.

El aspecto de los granos de yeso es análogo al de los granos de escoria granulada, siendo difícil diferenciarlos en determinados casos por examen microscópico; para ello basta tratar el cemento siderúrgico con el reactivo de Gonell (2 partes de una disolución al $5 \%$ de acetato de plomo y una parte de una disolución al $50 \%$ de ácido acético), los granos de escoria se cubren de $\mathrm{PbS}$, negro, mientras que los de yeso permanecen incoloros.

La acción prolongada del reactivo de Gonell disuelve parcialmente a los granos de clínker, de aquí que el recuento deba realizarse lo más rápido posible para que el tiempo de contacto sea mínimo (27).

Las partículas de yeso se reconocen y se diferencian también de las de escoria por examen con luz polarizada.

Los cementos en general y los siderúrgicos, en particular, tienen una fracción ferromagnética que debe eliminarse antes de realizar las preparaciones microscópicas.

Los diversos trabajos consultados, que determinan el contenido de escorias en los cementos siderúrgicos por vía microscópica, utilizan una fracción granulométrica que se encuentra comprendida entre 88 y $120 \mu$ para Berl-Lunge-D'Ans (30), entre 60 y $88 \mu$ para Janssens (27), entre 50 y $70 \mu$ para Brocard (34), entre 50 y $63 \mu$ para Musikas (35), entre 32 y $40 \mu$ según la norma DIN 1164 (50) y entre 30 y $40 \mu$. La fracción granulométrica elegida ha de tener una distribución tal de las partículas de escoria y de clínker que sea representativa del conjunto; hecho que, debido al distinto comportamiento de ambos componentes en la molienda del cemento, no se cumple, de aquí que se establezca un coeficiente de corrección, denominado "coeficiente de distribución", que tiene por objeto proporcionar un resultado apropiado que responda al valor del conjunto.

Para obtener la proporción en que se encuentran el clínker y la escoria en un cemento siderúrgico se deben contar los granos de cada material, teniendo en cuenta que este método es admisible cuando el tamaño y la forma de las partículas de ambos componentes en dicha fracción sean del mismo orden, ya que, en caso contrario, dicha proporción no respondería a la realidad.

Janssens (27) ha probado que en la fracción granulométrica intermedia, comprendida entre 60 y $88 \mu$, de un cemento se encuentra la mitad del yeso contenido en el mismo y que dicha fracción es representativa del conjunto cuando la molienda del clínker y de la escoria se hace independientemente a la misma finura, en un molino de laboratorio; sin embargo, cuando la molienda, a escala de laboratorio, se hace conjuntamente los valores que se obtienen, según los casos, son superiores o inferiores al real y en el caso de moliendas industriales la fracción intermedia tiene contenidos de escoria superiores al real llegando a ser hasta del $20 \%$, hecho que está de acuerdo con la estructura vítrea de la escoria (30).

El coeficiente de distribución se calcula por técnicas químicas determinando, por regla general, el poder reductor de la fracción granulométrica del cemento y del conjunto del mismo. Dicho coeficiente es la relación que existe entre el poder reductor del cemento y el de la fracción granulométrica. 
Musikas considera que, además del coeficiente de distribución, se debe introducir un coeeficiente de corrección másica por los distintos pesos específicos de la escoria y del clínker y otro coeficiente de forma (\% escoria contada/\% escoria después de la corrección másica $=$ coeficiente de forma teórico) para que se eliminen los errores debidos al aspecto, morfología, composición estructural, etc. de las partículas.

Los pesos específicos de la escoria $\left(2,80 \mathrm{~g} / \mathrm{cm}^{3}\right)$ y del clínker $\left(3,10 \mathrm{~g} / \mathrm{cm}^{3}\right)$ se pueden determinar experimentalmente a partir de los componentes puros extraídos del cemento objeto de estudio.

El cálculo, en peso, de los contenidos de escoria y de clínker es simple, basta para ello aplicar las siguientes expresiones:

$$
\begin{aligned}
& \% \text { escoria }(\% E)=100 \frac{2,80 E_{1}}{2,80 E_{1}+3,10 C_{1}} \\
& \% \text { clínker }(\% \quad C)=100 \frac{3,10 C_{1}}{3,10 C_{1}+2,80 E_{1}}
\end{aligned}
$$

en donde:

$E_{1}=$ número de partículas de escoria.

$C_{1}=$ número de partículas de clínker.

El número de partículas (granos) que se debe contar es de 1.000 .

Determinados autores tienen en cuenta el contenido de partículas de yeso, otros las consideran como si se tratase de partículas de clínker; en el primer caso, es decir, cuando se tiene en cuenta el yeso, el $\%$ en peso de escoria $(E)$ es:

$$
\% \text { de escoria }=\%\left(E-\frac{Y}{2}\right)
$$

en donde $Y$ es el contenido de yeso del cemento.

Aplicando el coeficiente de distribución se tendría el \% real de escoria presente en la mezcla:

$$
\% \text { de escoria }=\frac{\text { poder reductor del cemento }}{\text { poder reductor de }}\left(E-\frac{Y}{2}\right)
$$

en ciertos casos, especialmente cuando no se precisa exactitud, el coeficiente de distribución experimental se sustituye por el factor empírico $=0,88$.

A pesar de las correcciones establecidas los resultados obtenidos de un laboratorio a otro son bastante dispersos (29), hecho que hemos podido comprobar; sin embargo, Janssens considera que se trata de un procedimiento rápido y exacto, la precisión obtenida es, según dicho autor, de $\pm 1 \%$.

La norma DIN 1164 (50) calcula el contenido de escoria en los cementos siderúrgicos haciendo uso de una combinación de la técnica microscópica, utiliza un microscopio de polarización, y de una técnica de corrección química, determinando los compuestos de manganeso (II) y/o de calcio (II) presentes en la fracción granulométrica, en el cemento, en el clínker y en la escoria. Cuando se determina el calcio (II), éste debe correspon- 
der a los compuestos cálcicos, eliminando el contenido de yeso y corregido por la pérdida por calcinación tanto de la fracción granulométrica como del cemento objeto de estudio.

La fracción granulométrica es la comprendida entre 32 y $40 \mu$ y el número de partículas en total que se deben contar 1.000 .

El contenido de escoria en la fracción (\% E) por recuento, teniendo en cuenta la corrección másica, se calcula por medio de la expresión:

$$
\% \text { escoria }(\% E)=\frac{\rho_{1} E_{1}}{\rho_{1} E_{1}+\rho_{2} C_{1}}
$$

en donde:

$\rho_{1}=$ peso específico de la escoria (puede tomarse el valor $2,85 \mathrm{~g} / \mathrm{cm}^{3}$ );

$\rho_{2}=$ peso específico del clínker (puede tomarse el valor $3,15 \mathrm{~g} / \mathrm{cm}^{3}$ );

$E_{1}:=$ número de partículas de escoria.

$C_{1}=$ número de partículas de clínker.

La cantidad de escoria presente en el cemento, obtenida de la fracción granulométrica para eliminar los defectos de distribución, se calcula a partir de las cantidades $(C)$, expresadas en $\%$ en peso, de $\mathrm{CaO}$ y $\mathrm{MnO}$, determinadas experimentalmente en el cemento y en dicha fracción, por medio de la expresión:

$$
\% E \text { (corregida) }=\% E \frac{C \text { cemento }}{C \text { fracción }}
$$

o por medio de la siguiente, en la que se tiene en cuenta, además, el contenido medio de los elementos trazadores o guía $(C)$ en los componentes del cemento:

$$
\% E \text { (corregida) }=\% E+\frac{100(C \text { cemento }-C \text { fracción })}{C \text { escoria }-C \text { clínker }}
$$

Cuando se toman como elementos trazadores o guía los contenidos de $\mathrm{CaO}$ se pueden considerar como cifras medias $42 \%$ para la escoria y $65 \%$ para el clínker; por consiguiente, el valor del denominador de la expresión correspondiente será 23. Las cantidades de $\mathrm{CaO}$ del cemento y de la fracción deben estar exentas de la que corresponde al sulfato cálcico y corregidas por la pérdida al fuego.

El Comité Europeo de Normalización (CEN) tiene en fase de estudio muy avanzada una norma cuyo objeto es determinar, por un método microscópico, el contenido de escoria presente en los cementos de tres componentes: clínker de cemento portland-escoria de horno alto-regulador de fraguado (yeso).

La medida del contenido de escoria se realiza por recuento microscópico de parte de una fracción granulométrica del cemento comprendida entre 30 y $40 \mu$, introduciendo una corección másica, calculada o estimada, y una corrección de distribución basada en la determinación de los elementos trazadores o guía $\mathrm{Ca}$ (II) y $\mathrm{SO}_{4}{ }^{-2}$, expresados como $\mathrm{CaO}$ y $\mathrm{SO}_{3}$, presentes en el cemento y en la fracción granulométrica. El contenido de $\mathrm{CaO}$ de la mezcla y de dicha fracción corresponden a los compuestos cálcicos de ambas muestras, de los que se han eliminado, por cálculo, el correspondiente al sulfato cálcico. Se admite que la diferencia entre el contenido de $\mathrm{CaO}$ del clínker y de la escoria es $23 \%$. 
Las determinaciones químicas se efectúan sobre la muestra seca o calcinada, según que el contenido de escoria se refiera a la muestra seca o a la muestra calcinada.

El examen microscópico de la muestra se hace por luz transmitida o reflejada; el número de partículas, granos, que se deben contar es como mínimo 1.000 .

La desviación típica que se tiene por este método según que se considere la reproducibilidad entre distintos laboratorios o los valores repetidos en un mismo laboratorio sobre una muestra, es del $3 \%$ y del $1 \%$, respectivamente, siempre que el contenido de escoria sea menor del $80 \%$.

\subsubsection{Aplicación de técnicas físicas}

- Determinación del contenido de escorias por separación con líquidos densos

La técnica física que se aplica para determinar el contenido de escoria en los cementos siderúrgicos se basa en los diferentes pesos específicos de los componentes del sistema ternario: clínker de cemento portland-escoria-yeso* $\left(3,07\right.$ a 3,$15 ; 2,85$ a 2,90 y $2,30 \mathrm{~g} / \mathrm{cm}^{3}$, respectivamente), que permiten separarlos por sedimentación-centrifugación en líquidos de densidad apropiada, siempre que no reaccionen con las distintas fases sólidas, aplicando la mayoría de las veces una corrección de tipo químico.

En primer lugar se debe separar la fracción ferromagnética por medio de un imán y a continuación obtener una fracción granulométrica apropiada, representativa del conjunto, que cumpla con las condiciones físicas correspondientes para que tenga lugar la sedimentación y flotación de cada componente del sistema sólido-líquido.

El procedimiento de separación de la escoria, clínker y/o yeso por sedimentación, con o sin corrección química es una técnica simple que permite la determinación cuantitativa de dichos componentes (30) (33) (34) (35) (38) (51).

Berì-Lunge-D'Ans (30) utiliza la fracción granulométrica del cemento comprendida entre 60 y $80 \mu$ y la mezcla de yoduro de metileno y benzol para obtener líquidos de p.e. 3,00 y $2,90 \mathrm{~g} / \mathrm{cm}^{3}$ para conseguir en tres separaciones, con o sin centrifugación, clínker y escoria puros. Se considera necesario realizar el análisis químico de cada componente con el fin de confirmar la pureza de los mismos.

Duriez y Houlnick (38) determinan la cantidad de escoria y de clínker de los cementos siderúrgicos separando ambos componentes por sedimentación-centrifugación repetida a partir de la fracción granulométrica mayor de $15 \mu$, utilizando como líquidos densos una mezcla de yoduro de metileno y o-xileno.

El yeso queda en su mayor parte en la fracción separada menor de $15 \mu$, aproximadamente la mitad o dos tercios del yeso total. Se puede realizar la corrección correspondiente determinando por vía química su contenido en la muestra objeto de estudio.

Janssens (33) efectúa la separación de los componentes a partir de la fracción granulométrica comprendida entre 60 y $88 \mu$, utilizando como líquidos densos mezclas de yoduro de metileno y tetrabromuro de acetileno; la separación se hace por sedimentaciones sucesivas, con una eventual centrifugación, hasta conseguir los componentes puros. Janssens recomienda determinar el poder reductor de la escoria purificada para realizar el cálculo cuantitativo.

Brocard (34) realiza un estudio para determinar la cantidad de escoria presente en un cemento por recuento microscópico y por separación con líquidos densos, utilizando una mezcla de yoduro de metileno (13,6 \% en volumen) y bromoformo (86,4 \% en volumen)

* Regulador de fraguado. 
un p.e. $=2,95 \mathrm{~g} / \mathrm{cm}^{3}$ para obtener el clínker. Los resultados obtenidos van afectados de un error sistemático que, Brocard, atribuye a fenómenos superficiales de flotación, hecho que le llevó a utilizar agentes tenso activos.

Musikas (35) para conocer la cantidad de escorias presente en cementos con adiciones activas, por determinación del contenido de sulfuros en la escoria y en el aglomerante, separa por sedimentación-centrifugación los componentes de la mezcla, como se señala en el apartado 3.2.1. (c). Para ello utiliza la fracción granulométrica de cemento comprendida entre 50 y $63 \mu$ y como líquido denso dos mezclas a base de yoduro de metileno y o-xileno con p.e. de 3,00 y $2,70 \mathrm{~g} / \mathrm{cm}^{3}$, respectivamente, con lo que consigue obtener los componentes puros clínker, escoria y yeso.

Catharin (51) ha publicado recientemente un trabajo en el que da cuenta de un procedimiento para determinar cuantitativamente el contenido de escorias en los cementos por el método de separación de los componentes, con corrección química, por sedimentacióncentrifugación. Como líquidos densos utiliza mezclas de di-yodometano, 1,2 dibromoetano, bromoformo y 1,1,2,2, tetrabromoetano para obtener líquidos con un peso específico igual a $3,15 \mathrm{~g} / \mathrm{cm}^{3}$ y comprendido entre 2,98 y $2,89 \mathrm{~g} / \mathrm{cm}^{3}$ con lo que consigue separar los componentes puros clínker y escoria. Utiliza la fracción granulométrica comprendida entre 30 y $63 \mu$, eliminando los compuestos magnéticos. La corrección química se basa en determinar compuestos trazadores o guía presentes en la escoria, en el clínker, en el yeso $y$, por consiguiente, en el cemento objeto de estudio, como son los compuestos a base de $\mathrm{Ca}$ (II) o de sulfatos, valorando el contenido de $\mathrm{Ca}$ (II) o de $\mathrm{SO}_{4}{ }^{2-}$ que se expresan como $\mathrm{CaO}$ y $\mathrm{SO}_{3}$, respectivamente; por otra parte, determina otros elementos trazadores $\mathrm{o}$ guía propios de la escoria como son los de Mn (II) o los sulfuros que no se encuentran, fundamentalmente, en el yeso.

El elemento guía, o elemento trazador, $\mathrm{CaO}$ del clínker, del cemento y de la fracción granulométrica debe estar exento del correspondiente al sulfato cálcico.

Los análisis, tanto del cemento como de la fracción granulométrica y de sus componentes, se pueden referir a la muestra seca o a la muestra calcinada. Catharin lo hace a la muestra calcinada.

El Comite Europeo de Normalización (CEN) tiene muy avanzada la redacción de una norma para determinar el contenido de escoria en los sistemas ternarios: clínker de cemento portland-escoria de horno alto-regulador de fraguado (yeso) por sedimentación selectiva de los componentes clínker y escoria, tan puros como sea posible, utilizando líquidos densos y determinando dos elementos trazadores, o elementos guía, en el cemento y en las fracciones separadas de escoria y de clínker.

Para realizar la determinación del contenido de escoria se utiliza una fracción granulométrica comprendida entre 30 ó 40 y $80 \mu$ de la que se han eliminado las partículas metálicas por medio de un imán. La separación de los componentes puros clínker y escoria se consigue por medio de líquidos densos con un p.e. de $3,10 \mathrm{~g} / \mathrm{cm}^{3}$, para obtener el clínker, y un p.e. comprendido entre 2,87 y $2,89 \mathrm{~g} / \mathrm{cm}^{3}$ para separar la escoria; los líquidos densos se preparan a partir de mezclas de di-yodometano, ftalato de butilo o bromoformo.

La pureza de las fracciones separadas se comprueba por examen microscópico.

El cálculo de escoria presente en la mezcla se hace a partir del contenido de los elementos trazadores o guía determinados, compuestos de $\mathrm{Ca}$ (II), expresados como $\mathrm{CaO}$, presentes en el cemento y en las fracciones separadas de la escoria y del clínker, corregidos, es decir eliminando el correspondiente al sulfato cálcico, y de los compuestos de $\mathrm{Mg}$ (II), $\mathrm{Mn}$ (II) o sulfuros (expresados como $\mathrm{MgO}, \mathrm{MnO}$ y $\mathrm{S}^{2-}$ ) en el cemento y en las fracciones clínker y escoria que no se encuentren en el regulador de fraguado, sulfato cálcico. Por otra parte, para efectuar las correcciones oportunas, se debe determinar el contenido de $\mathrm{SO}_{4}{ }^{2-}$, expresado como $\mathrm{SO}_{3}$, en el cemento y en las fraciones obtenidas de clínker y de escoria. 
Las determinaciones se pueden hacer sobre muestra seca o sobre muestra calcinada. La utilización de los elementos trazadores o guía depende de la precisión de la técnica de trabajo y del contenido en los componentes (clínker y escoria); así se pueden emplear siempre que la diferencia entre dicho contenido en el clínker y en la escoria sea igual o mayor del $15 \%$ para $\mathrm{CaO}, 2 \%$ para $\mathrm{MgO}, 0,2 \%$ para $\mathrm{MnO}$ y $0,05 \%$ para $\mathrm{S}^{2-}$. Para calcular la cantidad de escoria presente en la mezcla se debe hacer uso, a ser posible, del tanto por ciento de $\mathrm{CaO}$ y de otro segundo elemento trazador $\left(\mathrm{S}^{2-}, \mathrm{MgO}\right.$ ó $\mathrm{MnO}$ ).

La desviación típica en todos los cementos siderúrgicos es del $3 \%$ para valores correspondientes a un cemento obtenidos en distintos laboratorios o del $1 \%$ para valores repetidos en un mismo laboratorio.

\section{B I B L I O G R A F I A}

(1) Pliego de Condiciones para la Recepción de Conglomerantes Hidráulicos. PCCH-64. IETcc. Madrid (1964).

(2) Prescripciones Técnicas Generales para la Recepción de Cementos. BOE n.o 206 y 207. RC-74 páginas 18.197-18.213 y págs. 18.299-18.311 (1975).

(3) Cement Standards of the world. Cembureau. París (1968). págs. 11-12.

(4) Garcia de Paredes, P.: Los conglomerantes siderúrgicos. Manuales y Normas IETcc. Madrid, (1959); pág. 49.

(5) TAylor, H. F. W.: La Química de los cementos. Cap. 13. Nurse, R. W.: Cementos de Escorias, páginas 51-52; Edit. Urmo, Bilbao (1967).

(6) Garcia de Paredes, P.: loc. cit. (4) pg. 67.

(7) SCHRöDER, F.: Slags in Modern Blastfurmace Processes. Part. IV. "Admixtures and Special Cement. Tokyo (1969), 151-155.

(8) Lea, F. M. and Desch.: The Chem. Of. Cement and Conc.; Edit. Arnold (1970). pg. 461 y sig.

(9) LEE, A. R.: Slag for roads. Its production, properties and uses. The Journ. of the Inst. of Highw. Eng. 11-29, (feb. 1969).

(10) Taylor, H. F. W.: La Química de los cementos, Cap. 2. WeLch, J. H.: Equilibrios de fases y quími$\mathrm{ca}$ a altas temperaturas en el sistema $\mathrm{CaO}-\mathrm{Al}_{2} \mathrm{O}_{3}-\mathrm{SiO}_{2}$ y sistemas relacionados, pg. 70; Edit. Urmo, Bilbao, (1967).

(11) Gaspar, D.: Mat. de Const., 159, 29-42 (1975).

(12) Garcia de Paredes, P.: loc. cit. (4) pg. 115.

(13) TAYlor, H. F. W.: La Química de los cementos, Cap. 2. Welch, J. H.: Loc. cit. págs. 76-77 y 85-89.

(14) KEIL, F.: Cemento. Fabricación, propiedades, aplicaciones, Edit. Técnicos Asociados, S. A.; Barcelona (1973), pg. 123.

(15) Mc. Murdie, H. F. and Insley, H.: J. Res. Nat. Bur. Stand. 16, 467; (1936), según Welch, J. J.; TAYlor, loc. cit. pág. 88.

(16) SCHRöDER, F.: Loc. cit. pág. 152.

(17) Musikas, N.: Rev. des Mat. de Const., 652-653, 30 (1970).

(18) Takashima, S. and Amano, F.: Rev. of the Fourteenth Gen. Meet. Tokyo, (may 1960) págs. 12-22.

(19) Hart, F.; GrigoriefF, P. N. und Chaikina, S. E.: según Janssens, P. Silicates Ind. 16, 129, (1951).

(20) KEIL, F. und GIlle, F.: Zement (1939), H. 28, p. 429; según Janssens, P.; Silic. Ind. 16, 129, (1951).

(21) Garcia de Paredes, P.: Las escorias siderúrgicas en la construcción. Manuales y Normas del IETcc. Madrid.

(22) Duriez, M. et Houlnick, M. CL.: Rev. des Mat. de Const. 422, 323, (1950).

(23) Burriel, F.; Lucena, F. y Arribas, S.: Química Analítica Cualitativa. Edit. Paraninfo. Madrid (1957), págs. 444-480.

(24) Curtman, L. J.: Análisis Químico Cualitativo. Ed. Marín; Barcelona (1944), pg. 416.

(25) Burriel, F.; Lucena, F y Arribas, S.: loc. cit. págs. 407 y 485. 
(26) Bermejo, F.: Química Analítica. Fac. Ciencias. Santiago (1974), pág. 767.

(27) Janssens, P.: Silic. Ind. 16, 129-134, (1951).

(28) Garcia de Paredes, P.: Loc. cit. págs. 94-95.

(29) Papadakis, M. et Venuat, M.: Fabrication et utilisation des Liants Hydrauliques. París, (1966), página 169.

(30) Berl-Lunge-D’Ans, J.: Métodos de análisis químico industrial. Edit. Labor (1945), tomo III, primera parte, págs. 373-374.

(31) RielH: Physik und technische Anwendung der Lumineszenz. Berlín (1941); según GaRcia De PaRedes, loc. cit. (21), págs. 30-31.

(32) Guttmann y Weiss: Zement 527-31, 547-49. (1926). Según Garcia de Paredes, loc. cit. (21), págs. 29-30.

(33) Janssens, P.: Loc. cit. (27).

(34) Brocard, J.: Rev. des Mat. de Const. 424, 10-17, (1951).

(35) Musikas, N.: Rev. des Mat. de Const.; 652-653. págs. 21-35 (1970).

(36) KEIL, F.: Proc. of the Third Inter. Symp. on the Chem. of Cem. London (1952), págs. 530-580.

(37) Schröber, F. and Vinkeloe, R.: Slags in Nodern Blastfurnace Processes. Part. IV Admixt. and Special Cements. Tokyo (1969), pág. 173.

(38) Duriez, M. et Houlnick, M. CL.: Loc. cit. págs. 325-327.

(39) McCoy, W. J.: Rock Products, 106 (oct. 1947); según JANssens, loc. cit. (35).

(40) KIllig, F.: Laboratorium für die Portland Zement Fabrik. (1925); según Janssens, loc. cit. (35).

(41) Catharin, P.: Zement und Beton 8, 11 (195'7); según Garcia de Paredes, loc. cit. (4), pág. 87.

(42) Burriel, F.; Lucena, F. y Arribas, S.: Loc. cit., pág. 236 .

(43) HAYDEN, R.: Zement-Kalk-Gips, 12, 329, (1951).

(44) KJELDAHL, según VoGeL, E.: Zement-Kalk-Gips, 5, 186, (1953).

(45) Anónimo: Zement-Kalk-Gips, 11, 416, (1953).

(46) WeLCH, J. H.: Loc. cit. pág. 91.

(47) Burriel, F.; Lucena, F. y Arribas, S.: Loc. cit. pág. 564.

(48) Clarke, H .T.: Manual de Análisis Orgánico; Edit. Marín, Barcelona (1945), pág. 127.

(49) Holleman, A. F.: Tratado de Química Orgánica; Edit. Marín, Barcelona (1946), pág. 426.

(50) DIN 1164, seite 5, Blatt 3 (juli 1967).

(51) CathaRIN, P.: Zement-Kalk-Gips, 2, 71-77, (1976). 
Las determinaciones se pueden hacer sobre muestra seca o sobre muestra calcinada. La utilización de los elementos trazadores o guía depende de la precisión de la técnica de trabajo y del contenido en los componentes (clínker y escoria); así se pueden emplear siempre que la diferencia entre dicho contenido en el clínker y en la escoria sea igual o mayor del $15 \%$ para $\mathrm{CaO}, 2 \%$ para $\mathrm{MgO}, 0,2 \%$ para $\mathrm{MnO}$ y $0,05 \%$ para $\mathrm{S}^{2-}$. Para calcular la cantidad de escoria presente en la mezcla se debe hacer uso, a ser posible, del tanto por ciento de $\mathrm{CaO}$ y de otro segundo elemento trazador $\left(\mathrm{S}^{2-}, \mathrm{MgO}\right.$ ó $\mathrm{MnO}$ ).

La desviación típica en todos los cementos siderúrgicos es del $3 \%$ para valores correspondientes a un cemento obtenidos en distintos laboratorios o del $1 \%$ para valores repetidos en un mismo laboratorio.

\section{B I B L I O G R A F I A}

(1) Pliego de Condiciones para la Recepción de Conglomerantes Hidráulicos. PCCH-64. IETcc. Madrid (1964).

(2) Prescripciones Técnicas Generales para la Recepción de Cementos. BOE n.o 206 y 207. RC-74 páginas 18.197-18.213 y págs. 18.299-18.311 (1975).

(3) Cement Standards of the world. Cembureau. París (1968). págs. 11-12.

(4) Garcia de Paredes, P.: Los conglomerantes siderúrgicos. Manuales y Normas IETcc. Madrid, (1959); pág. 49.

(5) TAYlor, H. F. W.: La Química de los cementos. Cap. 13. Nurse, R. W.: Cementos de Escorias, páginas 51-52; Edit. Urmo, Bilbao (1967).

(6) Garcia de Paredes, P.: loc. cit. (4) pg. 67.

(7) ScHröpER, F.: Slags in Modern Blastfurmace Processes. Part. IV. "Admixtures and Special Cement. Tokyo (1969), 151-155.

(8) Lea, F. M. and Desch.: The Chem. Of. Cement and Conc.; Edit. Arnold (1970). pg. 461 y sig.

(9) LEE, A. R.: Slag for roads. Its production, properties and uses. The Journ. of the Inst. of Highw. Eng. 11-29, (feb. 1969).

(10) TAYlor, H. F. W.: La Química de los cementos, Cap. 2. Welch, J. H.: Equilibrios de fases y química a altas temperaturas en el sistema $\mathrm{CaO}-\mathrm{Al}_{2} \mathrm{O}_{3}-\mathrm{SiO}_{2}$ y sistemas relacionados, pg. 70; Edit. Urmo, Bilbao, (1967).

(11) GASPAR, D.: Mat. de Const., 159, 29-42 (1975).

(12) Garcia de Paredes, P.: loc. cit. (4) pg. 115.

(13) TAYLOR, H. F. W.: La Química de los cementos, Cap. 2. Welch, J. H.: Loc. cit. págs. 76-77 y 85-89.

(14) KEIL, F.: Cemento. Fabricación, propiedades, aplicaciones, Edit. Técnicos Asociados, S. A.; Barcelona (1973), pg. 123.

(15) Mc. Murdie, H. F. and Insley, H.: J. Res. Nat. Bur. Stand. 16, 467; (1936), según Welch, J. J.; TAYlor, loc. cit. pág. 88.

(16) SCHRÖDER, F.: Loc. cit. pág. 152.

(17) Musikas, N.: Rev. des Mat. de Const., 652-653, 30 (1970).

(18) Takashima, S. and Amano, F.: Rev. of the Fourteenth Gen. Meet. Tokyo, (may 1960) págs. 12-22.

(19) Hart, F.; GrigoriefF, P. N. und ChaIkIna, S. E.: según Janssens, P. Silicates Ind. 16, 129, (1951).

(20) KeIL, F. und Gille, F.: Zement (1939), H. 28, p. 429; según Janssens, P.; Silic. Ind. 16, 129, (1951).

(21) Garcia de Paredes, P.: Las escorias siderúrgicas en la construcción. Manuales y Normas del IETcc. Madrid.

(22) Duriez, M. et Houlnick, M. CL.: Rev. des Mat. de Const. 422, 323, (1950).

(23) Burriel, F.; Lucena, F. y Arribas, S.: Química Analítica Cualitativa. Edit. Paraninfo. Madrid (1957), págs. $444-480$.

(24) Curtman, L. J.: Análisis Químico Cualitativo. Ed. Marín; Barcelona (1944), pg. 416.

(25) Burriel, F.; Lucena, F y Arribas, S.: loc. cit. págs. 407 y 485. 
(26) Bermejo, F.: Química Analítica. Fac. Ciencias. Santiago (1974), pág. 767.

(27) JANSSENS, P.: Silic. Ind. 16, 129-134, (1951).

(28) Garcia de Paredes, P.: Loc. cit. págs. 94-95.

(29) Papadakis, M. et Venuat, M.: Fabrication et utilisation des Liants Hydrauliques. París, (1966), página 169.

(30) Berl-Lunge-D'Ans, J.: Métodos de análisis químico industrial. Edit. Labor (1945), tomo III, primera parte, págs. 373-374.

(31) RIELH: Physik und technische Anwendung der Lumineszenz. Berlín (1941); según GARCIA DE PAREDES, loc. cit. (21), págs. 30-31.

(32) Guttmann y Weiss: Zement 527-31, 547-49. (1926). Según Garcia de Paredes, loc. cit. (21), págs. 29-30.

(33) Janssens, P.: Loc. cit. (27).

(34) Brocard, J.: Rev. des Mat. de Const. 424, 10-17, (1951).

(35) Musikas, N.: Rev. des Mat. de Const.; 652-653. págs. 21-35 (1970).

(36) KEIL, F.: Proc. of the Third Inter. Symp. on the Chem. of Cem. London (1952), págs. 530-580.

(37) Schröber, F. and Vinkeloe, R.: Slags in Nodern Blastfurnace Processes. Part. IV Admixt. and Special Cements. Tokyo (1969), pág. 173.

(38) Duriez, M. et Houlnick, M. CL. : Loc. cit. págs. 325-327.

(39) McCoy, W. J.: Rock Products, 106 (oct. 1947); según JANssens, loc. cit. (35).

(40) Killig, F.: Laboratorium für die Portland Zement Fabrik. (1925); según JANSSENS, loc. cit. (35).

(41) Catharin, P.: Zement und Beton 8, 11 (195'7); según Garcia de Paredes, loc. cit. (4), pág. 87.

(42) Burriel, F.; Lucena, F. y Arribas, S.: Loc. cit., pág. 236 .

(43) HAYDEN, R.: Zement-Kalk-Gips, 12, 329, (1951).

(44) KJEldahl, según Vogel, E.: Zement-Kalk-Gips, 5, 186, (1953).

(45) Anónimo: Zement-Kalk-Gips, 11, 416, (1953).

(46) Welch, J. H.: Loc. cit. pág. 91.

(47) Burriel, F.; Lucena, F. y Arribas, S.: Loc. cit. pág. 564.

(48) Clarke, H .T.: Manual de Análisis Orgánico; Edit. Marín, Barcelona (1945), pág. 127.

(49) Holleman, A. F.: Tratado de Química Orgánica; Edit. Marín, Barcelona (1946), pág. 426.

(50) DIN 1 164, seite 5, Blatt 3 (juli 1967).

(51) Catharin, P.: Zement-Kalk-Gips, 2, 71-77, (1976). 